\title{
Potencialidade do PIBID para além da formação de seus bolsistas: relatos de uma coordenadora
}

\author{
Thaiara Magro Pereira* \\ Caian Cremasco Receputi* \\ Daisy de Brito Rezende
}

\section{Considerações iniciais}

Vários grupos de pesquisa brasileiros vêm publicando trabalhos acerca da formação de professores, apontando o crescente interesse por essa temática e a necessidade da valorização desses profissionais nos cursos de formaçáo (Cericato, 2016; André, 2009). Os resultados desses e de outros estudos apresentam o consenso de que a formação inicial dos professores da educação básica, atualmente, não é adequada para enfrentar a problemática da sua área de atuação.

Nesse contexto, e a fim de aperfeiçoar a formação de professores, o Governo Federal implementou políticas de formação desses profissionais no âmbito

* Licenciada em Química pela Universidade Federal do Espírito Santo (UFES), doutoranda do Programa de Pós-Graduação Interunidades em Ensino de Ciências da Universidade de São Paulo (USP) e estudante do Grupo de Pesquisa Linguagem no Ensino de Química (LiEQui/USP).E-mail: thaiara.mp@hotmail.com.

** Licenciado em Química pela Universidade Federal do Espírito Santo (UFES). Mestre em Ensino de Ciências pelo Programa de Pós-Graduação Interunidades em Ensino de Ciências da Universidade de São Paulo (PIEC-USP). Doutorando do PIEC-USP. Membro do Grupo de Pesquisa Linguagem no Ensino de Química (LiEQui/USP). E-mail: caian.receputi@gmail.com.

*** Doutora em Química Orgânica e professora doutora do Departamento de Química Fundamental (IQUSP). Orientadora plena do Programa de Pós-graduação Interunidades em Ensino de Ciências da USP e líder do Grupo de Pesquisa Linguagem no Ensino de Química (LiEQui/USP).E-mail: dbrezend@gmail. com. 
das IES (Gatti et al, 2014), dentre eles o Programa Institucional de Bolsas de Iniciação à Docência (PIBID), que foi instituído pela Portaria normativa no 38 , de 12 de dezembro de 2007 (Brasil, 2007).

O PIBID é um programa vinculado a cursos de Licenciatura e Pedagogia que visa incentivar a formação de professores para a atuação no ensino básico, além de promover a valorização do magistério, pois promove a interaçáo universidade-escola. Para isso, o programa incentiva, dentre outras práticas, o estudo do contexto escolar, o desenvolvimento de açóes em diferentes espaços, tais como salas de aula e laboratórios, o desenvolvimento de açóes coletivas e interdisciplinares, a leitura e discussão de textos relativos à área do ensino, o desenvolvimento, teste e avaliação de estratégias de ensino e a participação em ações da escola (Brasil, 2013).

A execução do PIBID envolve a participação de "docentes das IES, responsáveis pela coordenação e desenvolvimento dos subprojetos, nas áreas de conhecimento que participam do programa" (Brasil, 2012, p. 7) e de professores da escola básica. Os bolsistas de iniciação à docência são alunos de Licenciatura que, no programa, realizam atividades e açóes com o acompanhamento do coordenador de área. Este, por sua vez, é um docente da universidade, responsável pela coordenação e desenvolvimento do subprojeto específico, que se vincula a um projeto institucional, mais abrangente, sob orientação do coordenador institucional. $\mathrm{Na}$ escola básica, a figura central é o supervisor, professor da escola onde o projeto é desenvolvido, que é o responsável por acompanhar e auxiliar os bolsistas no desenvolvimento de suas atividades na escola (Brasil, 2012).

O coordenador de área, foco principal deste artigo, é responsável pelo planejamento das atividades dentro e fora da escola e pela articulação das açôes do subprojeto nos dois espaços, universidade e escola. O coordenador de área tem um papel importante na definição das açóes e procedimentos do subprojeto que coordena, pois são os responsáveis diretos pelo planejamento de atividades e auxílio aos bolsistas licenciandos.

Destaca-se, ainda, a possibilidade das açóes desenvolvidas no âmbito do subprojeto PIBID repercutirem para o restante dos discentes de cursos de licenciatura, pois a participação no PIBID contribui para que o docente recontextualize saberes inerentes a sua prática, o que também modifica sua atuação no curso de licenciatura (Receputi, 2019).

Portanto, pretende-se, com este trabalho, apresentar uma investigação que objetivou identificar as principais contribuiçóes de um subprojeto PIBID, da área de Química, para o curso de Licenciatura em Química de uma Instituição de Ensino Superior (IES), segundo a coordenadora desse subprojeto. As experiências relatadas referem-se ao subprojeto PIBID-Química coordenado pela professora Tania Denise Miskinis Salgado (no período de 2009 a 2017), do Campus do Vale 
da Universidade Federal do Rio Grande do Sul (UFRGS).

\section{Formação da coordenadora}

Sobre sua trajetória formativa, a professora comenta:

Eu não sou licenciada em Química, eu sou bacharel em Química. Mas, desde que eu ingressei na universidade, eu trabalhei com educação em Química, eu sempre me integrei nessa área de educação em Química, embora eu tenha feito toda a minha formação na "área dura". Eu sou bacharel, mas eu nunca me interessei, eu vi que eu escolhi o curso errado, mas eu resolvi terminar para poder começar outra coisa. (Tania Denise Miskinis Salgado, 2016).

A professora cursou o bacharelado na UFRGS, terminando-o em 1983, ano em que não havia o oferecimento do curso de Licenciatura em Química, o que só ocorreu no ano de 1995. Tal fato pode explicar porque ela decidiu cursar Bacharelado em Química apesar de relatar que tinha interesse pela área de Ensino em Química.

A professora fez mestrado em Engenharia de Materiais na mesma Instituição. No ano de 1981, ela se tornou docente da instituição em que cursou o bacharelado (UFRGS), tendo atuado no Ensino de Química desde que ingressou como professora nessa universidade. Ela relata a intencionalidade, nessa ocasião, de se voltar para a área de ensino, fazendo um doutorado na área. Uma vez que, em sua instituição, não havia Programa de Pós-Graduação voltado para essa área, e por ter uma filha, o que a impossibilitava de se mudar para outro estado para cursar o doutorado na área intencionada, como Sáo Paulo, um dos poucos locais que, na época, ofereciam o curso, ela optou por realizar o doutorado em Ciências, na área de concentração Física Experimental, na UFRGS.

Daí eu fiz mestrado em Engenharia de Materiais, porque naquela época em que eu fiz mestrado, lá para os anos 80, não tinha mestrado em Química, e nem mestrado em Educação, na minha universidade. Entáo, eu fiz aquilo que estava disponível para mim, que era a Engenharia de Materiais. Então, meu mestrado foi nessa área, foi com radiaçóes. E, depois, eu passei um tempo sem fazer o doutorado, porque eu já queria fazer doutorado na área de Educação, mas eu tinha uma filha pequena, daí era complicado. Eu estava querendo fazer doutorado mas, para fazer doutorado na área da Educação em Ciências ou Educação em Química, eu teria que ir para São 
Paulo, na USP, Unicamp, alguma coisa assim. E, com criança pequena, eu vi que não havia condiçôes. Meu marido trabalhava em Porto Alegre e eu disse assim "bom, eu vou ter que esperar ela crescer um pouco". E, aí, nesse meio tempo, enquanto eu esperava, eu sempre trabalhei com Educaçáo em Química, sempre me identifiquei com isso. Eu trabalhava na área de Educação em Química para produção na área em Química, com o título de mestre. (Tania Denise Miskinis Salgado, 2016).

Pode-se depreender, da narrativa da coordenadora Tania, questóes relativas à inserção da mulher no meio acadêmico. Essa problemática quanto à inserção das mulheres na academia é histórica (Pereira; Favaro, 2017), devendo-se à representaçáo sobre as mulheres desde a época colonial no Brasil, em que se tinha a imagem da mulher como "sexo frágil" e responsável pelos afazeres do lar, dificultando sua inserção em graus mais elevados da educação, como o ensino superior. Essa realidade tem-se modificado lentamente, como mostrado pelos dados a seguir, relativos à atualidade.

A quantidade de ingressantes do sexo feminino na graduação, atualmente, é superior à daqueles do sexo masculino, embora a quantidade de concluintes de sexo masculino seja maior (Brasil, 2018). No caso específico dos cursos de graduação da área de Ciência Naturais e Exatas, apenas 33,1\% do total de graduados são mulheres (Unesco, 2015).

Estudos do World Economic Forum (WEF, 2016) mostram que a quantidade de ingressantes e concluintes do sexo feminino na pós-graduação das IESs brasileiras é maior do que a de pessoas do sexo masculino, tanto no Mestrado como no Doutorado. Com relação à atuação docente, as áreas de Física, Química, Biologia, Engenharia e Tecnologia são as que possuem um número menor de mulheres em níveis mais avançados da carreira acadêmica (Unesco, 2015).

Com relação ao número de docentes de IES com bolsa de produtividade em pesquisa do Conselho Nacional de Desenvolvimento Científico e Tecnológico $(\mathrm{CNPq})$ nas áreas das Exatas, atualmente, as mulheres detêm somente $35 \%$ delas, número que também diminui conforme se avança na carreira acadêmica (Brasil, 2014).

Pode-se observar, por esses dados, que, apesar das mulheres, atualmente, serem a maioria dentre os ingressantes na graduação, elas tornam-se minoria nos estágios subsequentes da carreira (término da graduação, pós-graduação e atuação 
docente).

Portanto, apesar de se diagnosticar uma mudança quanto à inserção da mulher na graduação e na pós-graduação, há uma série de questôes que se relacionam à permanência das mulheres na academia e à sua progressão na carreira docente.

No caso da coordenadora Tania, pode-se observar que, apesar dos impasses relatados quanto à sua inserção na área de Ensino ou Educação, por meio de formação acadêmica específica, a professora tinha experiência na área de Ensino de Química, antes de ser coordenadora do subprojeto PIBID-Química, tanto lecionando disciplinas de interface ${ }^{1}$ do Ensino de Química, como realizando pesquisas nessa área. A professora comenta que assumir a coordenação do PIBID resultou dessa trajetória, mas que nem por isso foi fácil, para ela, coordenar o subprojeto PIBID-Química, sendo sempre um desafio.

\section{Concepção de formação de professores e de docência}

A professora destaca algumas características importantes do que seria um bom professor para pensar o processo de formação dos licenciandos do PIBID. Algumas das características destacadas são: atuar como produtor do próprio material; buscar se desvincular do ensino tradicional, ${ }^{2}$ dominar o conteúdo específico de sua área; saber trabalhar em grupo com outros professores com um objetivo comum.

O professor da escola deve ser um elaborador, um produtor do seu próprio material didático [...]. [É importante que o professor da escola opte por] atividades mais alternativas, que náo sejam tão ligados apenas a passar conteúdo teórico, [...] atividades diferenciadas em sala de aula. (Tania Denise Miskinis Salgado, 2017).

Nessa perspectiva, alguns dos elementos citados pela professora como essenciais à formação de professores, no âmbito do PIBID, são: a adaptação à realidade escolar e ao trabalho do seu tutor (o supervisor, no caso do PIBID);

1 Disciplinas de interface se definem como aquelas que "promovem a integração entre os saberes químicos e os pedagógicos e têm como objeto de estudo os aspectos específicos da aprendizagem de química na sala de aula, mas em uma perspectiva crítica e de pesquisa" (Kasseboehmer; Farias, 2012, p. 101).

2 Entende-se por ensino tradicional, a prática educativa caracterizada pela transmissão dos conhecimentos historicamente acumulados pela humanidade, na forma dos conteúdos disciplinares que são descaracterizados e descontextualizados de sua fonte de origem, a atividade científica. Essa ação é atribuída ao professor, detentor do conhecimento, em um espaço físico, a sala de aula, agindo independentemente dos interesses dos alunos, em uma ação mecânica de instrução (Mizukami, 1986). 
o desenvolvimento de saberes experienciais na sala de aula, dentre os quais os relacionados ao trabalho em grupo, à gestáo da sala de aula (por exemplo, como atender o aluno) e à transposição didática; a multiplicidade de olhares sobre o conteúdo, ou seja, relacionar temas com conteúdos específicos de sua área específica e de outras áreas do conhecimento; a proposição de atividades na perspectiva interdisciplinar; o contato com professores especializados na área específica de formação do licenciando, nesse caso a Química.

Com essas oficinas interdisciplinares, os bolsistas aprendem, principalmente, a olhar o tema que antes eles viam só sob o ponto de vista da disciplina deles. Ver que esse tema tem outras possibilidades. E aprendem, também, sobre o trabalho interdisciplinar em si. (Tania Denise Miskinis Salgado, 2016).

Os bolsistas também estão vendo que, mesmo que um assunto tenha sido formalmente estudado em sala de aula, eles não conseguem aplicar para aquela situaçãa. Com isso, eles têm que adquirir um pouco de jogo de cintura, ter certa flexibilidade. E têm que estar preparados. Aquele tema ele tem que saber muito bem, porque ele não sabe de que lado vai vir a pergunta do aluno. (Tania Denise Miskinis Salgado, 2016).

[...] a gente tem oportunizado para os bolsistas vários momentos diferentes de atuação, envolvendo-os em vários momentos diferentes de atuação, não só na sala de aula. Porque a gente acha que as outras atividades enriquecem a formação do bolsista. (Tania Denise Miskinis Salgado, 2017).

Depreende-se dos trechos acima que, para a professora, o maior número de atividades diferenciadas é positivo para incitar o aluno a vivenciar as múltiplas realidades inerentes ao contexto escolar, o que é importante para sua formação docente.

\section{Contribuição do PIBID para a formação da coordenadora}

A professora relata que, no início do projeto, as açóes eram desenvolvidas visando auxiliar na melhoria da educação básica, pela realização de açóes pontuais na escola que possibilitassem a melhoria da nota do Índice de Desenvolvimento da Educação Básica (IDEB), como pode mostrado no trecho a seguir:

Eu acho que, no início, quando o PIBID começou, a gente pensava muito mais que o foco do projeto era a melhoria da qualidade da educaçáo básica. 
$\mathrm{Na}$ verdade, essa era a intenção do projeto. Um dos objetivos era o de elevar a nota do IDEB, eles queriam elevar o IDEB. Tanto que, para a escolha das primeiras escolas, era critério imprescindível ter IDEB baixo para [a escola] entrar no PIBID, lá no primeiro projeto, lá bem no início. (Tania Denise Miskinis Salgado, 2017).

Essa exigência pode ser reflexo dos objetivos iniciais definidos para o PIBID, como apresentado no trecho abaixo:

As atividades do Programa deverão ser cumpridas tanto em escolas com Índices de Desenvolvimento da Educação Básica - IDEB abaixo da média da regiáo/estado quanto naquelas que tenham experiências bem sucedidas de trabalho pedagógico e de ensino-aprendizagem, de modo a apreender diferentes realidades e necessidades da Educação Básica e de contribuir para a elevação do IDEB, aproximando-o do patamar considerado no Plano de Metas Compromisso Todos pela Educação. (Brasil, 2009, Art. 8º).

Porém, esse objetivo foi se deslocando para a formação do licenciando, com a justificativa de que, se este for bem formado, desempenhará melhor sua função na educação básica, o que possibilitaria a melhoria da escola.

Eu vejo que a gente também amadureceu essa questão de que o nosso foco é a formação do futuro docente, valorizar experiências de formação para ele, para ser um bom professor, um professor motivado e, inclusive, para trabalhar na educação básica pública no futuro. [...] Nosso foco está muito mais na formação de professores do que na melhoria da qualidade da educação básica. A melhoria da qualidade da Educação Básica é uma consequência da melhoria da formaçáo do professor. [...] Nós vamos melhorar a educação básica pela via do professor bem formado e não ir lá e fazer tudo o que o governo não faz. [...] Para a melhoria da educação básica, como um todo, são necessárias outras açóes; isso é papel do governo. [...] Quando surgiu o projeto, em 2008, fizemos várias propostas de atividades, mas a gente não tinha isso tão claro, de que não era possível aumentar o IDEB de uma escola só com a nossa ação. Estava nas metas, mas não é disso que a gente vai conseguir dar conta. Mas dar conta de melhorar a formação do professor, a gente dá. (Tania Denise Miskinis Salgado, 2017).

A professora entende que a melhoraria da educação básica é um processo que demanda grande investimento, sendo, um deles, a formação do professor. Porém, a melhoria da educação básica não depende somente da formação de professores. 
Embora os objetivos do PIBID (os quais a professora entendia serem objetivos do Programa) tenham sido modificados ao longo do tempo, as açóes desenvolvidas no contexto da escola ainda se voltavam para atender sua realidade, uma vez que a professora concebe tais açóes como necessárias para a formação do licenciando.

Eu acho que grande parte das atividades [desenvolvidas no âmbito do PIBID, no contexto escolar] são diversificadas por termos um espírito de [...] atender a necessidade da escola. [...] Não no sentido de atender demandas pontuais, mas de atender a realidade daquela escola, até onde ela está situada também, que público ela atinge. (Tania Denise Miskinis Salgado, 2016).

Depreende-se que um dos aspectos referentes à concepção da professora sobre a formação do licenciando ancora-se na proposição de múltiplas tarefas, possível reflexo dos objetivos iniciais do PIBID e das problemáticas enfrentadas pela escola da educação básica, diagnosticadas no âmbito do subprojeto PIBID. Essa característica, presente no começo do PIBID, se perpetua até os dias atuais, pois a coordenadora acredita que isso faz parte da formaçáo do licenciando e que contribui para sua futura atuação.

E acho que, também, é um pouco da gente não querer se acomodar. Essas outras atividades todas, essas oficinas interdisciplinares, essa coisa de ir lá na escola do campo, de fazer Olimpíadas de Química, são um monte de coisas que náo são obrigaçóes do PIBID. [...] Essas oficinas interdisciplinares são um desafio para nós coordenadores também, porque ninguém tem uma receita. Tenho uma colega que diz que fazer interdisciplinaridade é fazer aquilo que ninguém sabe fazer direito e que ninguém sabe definir direito o que é. (Tania Denise Miskinis Salgado, 2017).

Sobre as ações desenvolvidas no âmbito do subprojeto PIBID, Tania esclarece que, ao longo do projeto, algumas açôes foram sendo aprofundadas teoricamente com base nos autores da área Educação/Ensino de Química.

No primeiro momento, isso não era tão claro para nós, essa clareza foi sendo desenvolvida na medida em que as ações foram sendo desenvolvidas; quando a gente colocou o bolsista para ficar dentro da sala de aula com o professor, para acompanhá-lo, praticamente durante o turno inteiro. Então, esse tipo de coisa a gente percebeu que é, sim, uma ação de formação com referencial teórico por trás, embora a gente náo tivesse isso tão claro no início. (Tania Denise Miskinis Salgado, 2017). 
Isso se deve à necessidade de, ao se perceber uma problemática enfrentada na escola, tentar superá-la com fundamento nos referenciais da área de Educação/ Ensino de Química. Este é um processo cíclico que demanda muita leitura e aprofundamento teórico, como observado em outros projetos (Pereira et al., 2020). Esse aprofundamento teórico ocorre nos subprojetos, na maioria dos casos, através da discussão do aporte teórico em grupo, tendo como motivador alguma situação vivida entre os bolsistas em sala de aula ou a ser desenvolvida nesse espaço. Por exemplo, no planejamento de alguma estratégia pedagógica a ser desenvolvida no contexto escolar. Nesse sentido, as açóes planejadas no âmbito do subprojeto pautam-se "pela relação entre as bases teóricas estudadas e as açóes práticas, potencializando a superação de problemas identificados nos processos de ensino e aprendizado dos alunos da Escola Básica" (Pereira et al., 2020).

\section{Contribuição do PIBID para o curso: disciplina}

Pode-se ressaltar, da entrevista da professora Tania, o fato de uma disciplina, anteriormente eletiva, ter-se tornado obrigatória para o curso de Licenciatura em Química da UFRGS, devido à influência do PIBID na unidade acadêmica. Tratava-se de uma eletiva para os cursos de Licenciatura em Química e Biologia, inicialmente, e de Física, posteriormente. Conta-se, a seguir, um pouco da trajetória dos subprojetos PIBID-Física, PIBID-Química e PIBID-Biologia, que possibilitou a criação dessa disciplina.

As oficinas interdisciplinares ${ }^{3}$ surgiram de uma ideia em comum da professora Tania e a coordenadora, na época, do subprojeto PIBID-Física do Campus do Vale da UFRGS. Existia uma relação interpessoal entre as duas coordenadoras, o que facilitou o surgimento da ideia do desenvolvimento, em conjunto, dessas oficinas. Essas oficinas advêm, também, da proximidade existente entre as duas disciplinas, ambas do campo das Ciências Naturais.

Nós, também, nos conhecemos de longa data, sempre trocamos muitas ideias a respeito das açóes que desenvolvemos no PIBID. A gente já tinha uma afinidade pessoal e de pensamento, então surgiu a ideia de 'quem sabe a gente junta isso'. (Tania Denise Miskinis Salgado, 2016).

Essa proposta, relatada neste artigo, surgiu da relação entre subprojetos PIBID disciplinares. Mas, há de se ressaltar a existência de subprojetos PIBID interdisciplinares, que envolvem a participação de licenciandos de diferentes áreas do conhecimento, sendo a interdisciplinaridade uma característica implícita desses projetos. 
A professora relata que o trabalho interdisciplinar sempre foi um desafio durante sua atuaçáo no PIBID, devido à sua complexidade. Uma das características relatadas é que, para essas oficinas serem bem desenvolvidas, além de ser necessária a existência de uma relação entre os conteúdos específicos das diferentes áreas, é indispensável que os sujeitos tenham uma boa relação interpessoal, pautada em um objetivo comum, aspecto que ela denomina interpessoalidade.

A gente descobriu que, na verdade, a oficina interdisciplinar depende não só da interdisciplinaridade de conteúdo, mas da interpessoalidade também. Por isso que eu disse que interpessoalidade não significa que se vai juntar professor de Química com professor de Física naquela escola e a interdisciplinaridade vai acontecer. Se eles não tiverem horários compatíveis, se eles não tiverem afinidade de ideias e afinidade pessoal [...], trabalharem bem juntos, não adianta querer dizer que o professor de Física vai ter interpessoalidade com o professor de Biologia [...]. (Tania Denise Miskinis Salgado, 2016).

Apesar do desafio relatado, realizaram-se algumas oficinas sobre temas diversificados, por exemplo, oficina de fotografia e oficina de radiaçôes (entre PIBID-Química e PIBID-Física), e oficina forense (entre PIBID-Química, PIBIDFísica e PIBID-Biologia). ${ }^{4}$ Essas oficinas, além de repercutirem positivamente nas escolas, originaram trabalhos acadêmicos, realizados pelos licenciandos bolsistas, premiados em eventos da própria instituição.

[...] foi uma coisa bem lúdica, fez muito sucesso. Quando alguém ouvia que estava aplicando essa oficina [oficina de fotografia], já pedia para aplicar em outras escolas. A gente tinha os PIBID-Química e PIBID-Física, na época, e aplicamos em todas as escolas parceiras, não em todas as turmas, mas aplicamos em todas as escolas e, também, em algumas outras escolas, que não eram [participantes] do PIBID. (Tania Denise Miskinis Salgado, 2016).

4 Pode-se saber mais sobre essas oficinas nos trabalhos: SALGADO, Tania Denise Miskinis; SILVA, Maria Teresinha Xavier. Oficinas interdisciplinares: integrando o PIBID química e o PIBID física na UFRGS. In: ENCONTRO DE DEBATES SOBRE O ENSINO DE QUÍMICA, 33, 2013, Ijuí. Anais... Ijuí: UNIJUÍ, 2013. Disponível em: <https://www.publicacoeseventos.unijui.edu.br/index.php/edeq/ article/view/2833>. Acesso em: 29 fev. 2020; VIEIRA, Anna Fatima; SANTOS, Laís Corrêa dos; AGUIAR, Luiza Soares de; ADOLFI, Leonardo Vilanova; FARIAS, Reni Campos; LEON, Sandro Roberto dos Santos Silva de; MIGUEL, Ivone Rosária Depperman; PASSOS, Camila Greff; SIRTORI, Carla; SALGADO, Tania Denise Miskinis. Química forense: abordagem de um tema popular entre adolescentes em uma oficina do PIBID/Química da UFRGS. In: ENCONTRO NACIONAL DE ENSINO DE QUÍMICA, 18, 2016, Florianópolis. Anais... Florianópolis: UFSC, 2016. Disponível em: <http://www.eneq2016.ufsc.br/anais/resumos/R0272-2.pdf>. Acesso em: 29 fev. 2020. 
Os aspectos positivos relatados pela professora com relação às oficinas interdisciplinares, e o caráter formativo atribuído ao trabalho interdisciplinar (no que concerne, principalmente, à formação docente), motivaram a criação de um curso de extensão sobre a temática da interdisciplinaridade, para professores da educação básica, aberto também para os licenciandos da UFRGS. Esse curso foi realizado no segundo semestre de 2016 e intitulou-se "Buscando Interfaces Disciplinares no Ensino de Ciências". Uma das atividades do curso visava instrumentalizar o professor para que ele, em conjunto com outros professores, elaborasse uma proposta interdisciplinar, considerando o contexto escolar em que atua, o que mostra a intenção de possibilitar que essa abordagem seja transposta para a sala de aula.

Essas experiências, tanto no contexto do PIBID, a partir da elaboração e desenvolvimento das oficinas interdisciplinares, quanto no curso de extensão, resultaram na criação, em 2017, de uma disciplina eletiva sobre interdisciplinaridade a ser ministrada nos cursos de licenciatura da área de Ciências Naturais do Campus do Vale (Ciências Biológicas, Física e Química), da UFRGS. De acordo com as autoras do projeto, em um artigo que discorre sobre a criação desta disciplina (Salgado; Moço; Silva, 2019, p. 202): "pretendeuse transpor a experiência adquirida no PIBID para os currículos dos cursos de formação docente".

Alguns dos objetivos dessa disciplina podem ser depreendidos da narrativa da professora Tania. Esses objetivos, dentre outros, constam do artigo citado anteriormente, e estão relatados a seguir:

Como objetivos específicos, pretendeu-se que os futuros docentes fossem capazes de: articular os conhecimentos das três áreas das Ciências da Natureza, por meio de temas geradores interdisciplinares; compreender a importância do diálogo entre as áreas para a formação científica de seus alunos; realizar trabalhos em equipes interdisciplinares, habituando-os a ouvir, refletir, compreender e respeitar as diferentes opinióes e formas de interpretar o mundo; compreender e explicar os fatos que, frequentemente, são noticiados pela imprensa e até nas redes sociais com relação ao campo interdisciplinar do conhecimento em Ciências da Natureza; trabalhar esses temas em uma perspectiva adequada à sala de aula do Ensino Básico. (Salgado; Moço; Silva, 2019, p. 202).

Para se alcançarem esses objetivos, as professoras da disciplina, coordenadoras dos subprojetos PIBID supracitados, utilizaram-se da perspectiva interdisciplinar para fundamentar açóes desenvolvidas na disciplina, desde estudos acerca da fundamentação teórica, até a elaboração e desenvolvimento de propostas 
interdisciplinares. Tal caráter estava presente na disciplina por meio da atuação das professoras, que se fazia em conjunto, com as três em sala de aula em todos os momentos da disciplina e, também, com a proposição de açôes que envolvessem os alunos de modo a efetivar a interpessoalidade, que a professora Tania enfatiza em sua narrativa, abordando-a como um aspecto inerente à interdisciplinaridade.

Essa ênfase ao caráter interdisciplinar inerente à disciplina é relatada, ainda, em Salgado, Moço e Silva (2019). Por meio desse relato, pode-se compreender que existia uma aposta entre as docentes de que, para formar professores que apresentassem as habilidades necessárias para o trabalho interdisciplinar, em sua futura atuaçáo docente, elas deveriam, primeiramente, transpor a barreira estabelecida pelo caráter disciplinar da própria instituição e dos cursos aos quais estavam vinculadas. Essa barreira se refere à estrutura disciplinar de atuação das docentes (vinculadas a departamentos de diferentes unidades específicas) e à estrutura disciplinar do currículo dos cursos de formação de professores, em que cada disciplina, mesmo aquelas de interface, geralmente, é atribuída a um único docente.

Pode-se inferir, da análise da narrativa e do relato exposto em Salgado, Moço e Silva (2019) o papel fundamental do PIBID para a estruturação dessa disciplina. O PIBID possibilitou que a coordenadora Tania, juntamente com as coordenadoras dos outros subprojetos, amadurecesse a compreensão (no sentido de descobrir as formas de se trabalhar interdisciplinarmente) das características intrínsecas ao trabalho interdisciplinar devido à elaboração das oficinas interdisciplinares. A liberdade de desenvolvimento de açóes desse tipo, que possibilita a relação entre atores de diferentes áreas de conhecimento, foi fundamental para a implementação destas práticas.

\section{Considerações finais}

A análise da narrativa da professora Tania em relação ao PIBID permitiu identificar questóes relacionadas tanto a sua inserção na área de Ensino de Química, como a suas concepçóes sobre a formação de professores. Esses aspectos permitiram inferir as motivações subjacentes tanto à proposição das ações desenvolvidas no âmbito do subprojeto sob sua coordenaçáo, como ao surgimento de um produto devido a suas experiências no PIBID, que contribuíram diretamente para a reestruturação do curso de formação de professores de Química da UFRGS.

O PIBID apresentou uma importância significativa em sua formação continuada, intensificando suas relaçóes com a área do Ensino de Química. Outro resultado importante das açôes do subprojeto PIBID sob sua coordenação, é a 
proposição de uma disciplina desenvolvida segundo as experiências ali vivenciadas. Essas açôes só foram possíveis pela continuidade na coordenação do PIBID. Tânia permaneceu como coordenadora durante nove anos, o que proporcionou reflexôes sobre as problemáticas vivenciadas por docentes e discentes na educação básica, tendo-se como produto o desenvolvimento de cursos e disciplinas que levassem em consideração a vivência dessas questôes.

Desse modo, pode-se observar que esse programa apresenta importância em diferentes vertentes, desde a formação do licenciando bolsista, até aquela de outros licenciandos do curso de formação inicial de professores, além do impacto na formação continuada do coordenador do subprojeto em análise.

\section{Referências}

ANDRÉ, Marlí Eliza Dalmazo Afonso de. A produção acadêmica sobre formação de professores: um estudo comparativo das dissertaçóes e teses defendidas nos anos de 1990 e 2000. Formação Docente, Belo Horizonte, v. 1, n. 1, p. 41-56, ago./dez. 2009.

BRASIL. Ministério da Educação. Gabinete do Ministro. Portaria nº 38 de 12 de dezembro de 2007. Dispóe sobre o Programa Institucional de Bolsa de Iniciação à Docência - PIBID. Diário Oficial da União, Brasília, DF, 13 dez. 2007. p. 39.

Ministério da Educação. Coordenação de Aperfeiçoamento de Pessoal de Nível Superior. Portaria Normativa CAPES no 122, de 16 de setembro de 2009. Dispóe sobre o PIBID - Programa Institucional de Bolsa de Iniciação à Docência, no âmbito da CAPES. Disponível em: <http://www.capes.gov.br/images/stories/ download/bolsas/PortariaNormativa122_PIBID.pdf>. Acesso em: 2 jun. 2020.

. Ministério da Educação. Coordenação de Aperfeiçoamento de Pessoal de Nível Superior. Diretoria de Formação de Professores da Educação Básica - DEB. Relatório de Gestão 2009-2011. Disponível em: < https://www.capes.gov.br/images/stories/download/ bolsas/DEB_Pibid_Relatorio-2009_2011.pdf>. Acesso em: 2 jun. 2020.

. Ministério da Educação. Gabinete do Ministro. Portaria no 096, de 18 de julho de 2013. Dispóe sobre o Programa Institucional de Bolsa de Iniciação à Docência - PIBID. Diário Oficial da União, Brasília, DF, 18 jul. 2013. p. 11.

. Ministério da Educação. Instituto Nacional de Estudos e Pesquisas Educacionais Anísio Teixeira. Censo da Educação Superior 2017 - Divulgação dos principais resultados. Brasília, DF. 2018. Disponível em: <https://abmes.org.br/arquivos/documentos/ principais\%20resultados.pdf 5 . Acesso em: 2 jun. 2020.

. Coordenação de Aperfeiçoamento de Pessoal de Nível Superior. Bolsas no país: 
distribuição segundo grande área e sexo do bolsista. 2014. Disponível em: <http://cnpq.br/ documents/10157/adb76b26-3a8a-4478-9605-e7325e9de50e>. Acesso em: 2 jun. 2020.

CERICATO, Itale Luciane. A profissão docente em análise no Brasil: uma revisão bibliográfica. Revista Brasileira de Estudos Pedagógicos, Brasília, v. 97, n. 246, p. 273-289, mai./ago. 2016.

GATTI, Bernardete Angelina; ANDRÉ, Marlí Eliza Dalmazo Afonso de; GIMENES, Nelson Antonio Simáo; FERRAGUT, Laurizete. Um estudo avaliativo do Programa Institucional de Bolsa de Iniciação à Docência (PIBID). Textos FCC, São Paulo, v. 41, p. 1-120, set. 2014.

KASSEBOEHMER, Ana Cláudia; FARIAS, Sidilene Aquino. Conteúdos das disciplinas de interface atribuídos a prática como componente curricular em cursos de licenciatura em Química. Alexandria: Revista de Educação em Ciência e Tecnologia, Florianópolis, v. 5, n. 2, p. 95-123, set. 2012.

MIZUKAMI, Maria da Graça Nicoletti. Ensino: as abordagens do processo. São Paulo: EPU, 1986.

SALGADO, Tania Denise Miskinis; MOÇO, Maria Cecilia de Chiara; SILVA, Maria Teresinha Xavier. Interfaces Disciplinares no Ensino e Ciências: Uma Perspectiva Docente. Química Nova na Escola, São Paulo, v. 41, n. 2, p. 200-209, mai. 2019.

PEREIRA, Ana Cristina Furtado; FAVARO, Neide de Almeida Lança Galvão. História da mulher no ensino superior e suas condiçôes atuais de acesso e permanência. In: CONGRESSO NACIONAL DE EDUCAÇÃO, 13, Curitiba, 2017. Anais... Curitiba: EDUCERE, 2017. Disponível em: <https://educere.bruc.com.br/arquivo/pdf2017/26207_12709.pdf>. Acesso em: 2 jan. 2020.

PEREIRA, Thaiara Magro; RECEPUTI, Caian Cremasco; MARAGLIA, Pedro Henrique, VOGEL, Marcos, REZENDE, Dayse de Brito. Contribuiçóes do PIBID para a formação inicial de licenciandos em Química: análise de Teses e Dissertaçóes. Química Nova na Escola, São Paulo, v. 42, n. 1, p. 56-67, fev. 2020.

RECEPUTI, Caian Cremasco. Percep̧ốes de professores de Licenciaturas em Química sobre "experimentação", na perspectiva da Teoria das Representaçôes Sociais. Dissertação (Mestrado em Ensino de Ciências) - USP, São Paulo SP, 2019.

UNESCO - Organização das Naçôes Unidas para a Educação, a Ciência e a Cultura. UNESCO Science Report. towards 2030. Paris: UNESCO Publishing, 2015. Disponível em: <https://unesdoc.unesco.org/ark:/48223/pf0000235406>. Acesso em: 29 fev. 2020.

WEF - World Economic Forum. The Global Gender Gap Report 2016. Geneva/Suíça: WEF, 2016. 


\title{
Fontes orais
}

SALGADO, Tania Denise Miskinis [61 anos]. [jul. 2016]. Entrevistador: Thaiara Magro Pereira. Porto Alegre, RS, 26 jul. 2016.

SALGADO, Tania Denise Miskinis [61 anos]. [set. 2017]. Entrevistador: Thaiara Magro Pereira. Porto Alegre, RS, 14 set. 2017.

Resumo: Este artigo tem como objetivo relatar a análise da narrativa de uma coordenadora de um subprojeto PIBID-Química sobre as açóes desenvolvidas em seu âmbito, buscando identificar as contribuições desse projeto para sua formação continuada e para a formação inicial de professores de Química. A coordenadora relata desde sua trajetória formativa até sua inserção no PIBID, destacando as açóes desenvolvidas no subprojeto e as implicaçóes dessas ações na formação dos licenciandos em Química. Os resultados da análise da narrativa indicam que I) o PIBID contribuiu para sua formação continuada; II) a multiplicidade de ações desenvolvidas pelo subprojeto sob sua coordenação eram delineadas tendo como base a realidade da escola; e, III) as experiências realizadas no âmbito do PIBID permitiram a criação de uma disciplina que tem contribuído para a formação dos professores da Instituição de Ensino Superior à qual a coordenadora está vinculada.

Palavras-chave: História Oral. PIBID. Formação de professores. Coordenador de área.

\section{Potential of the PIBID beyond the training of its scholarships holders: reports of a coordinator}

\begin{abstract}
This article aims to report the analysis of the narrative of a coordinator of a subproject PIBID-Química (acronym from Portuguese for a Federal Program established in Brazil for the improvement of the initial training of High School Science teachers; in this case, Chemistry) on the actions developed in its scope, seeking to identify the contributions of this project to her continued formation and the initial formation of Chemistry teachers. The narrative refers to her insertion on PIBID program. Highlights were the design of project actions and their implications to Chemistry undergraduates' formation. Analysis of the narrative indicates that: I) PIBID contributed to continued formation; II) actions developed in the project under her coordination are diverse due to school reality; and, III) PIBID experience inspired the creation of a discipline that has contributed to the formation of teachers in the Higher Education Institution to which the coordinator is linked.
\end{abstract}

Keywords: Oral History. PIBID. Initial teacher training. Area coordinator.

Recebido em 29/03/20

Aprovado em 18/05/20 